\title{
Molecular Aspects of Plant Growth Promotion and Protection by Bacillus subtilis
}

\author{
Christopher Blake, Mathilde Nordgaard Christensen, and Ákos T. Kovács ${ }^{\dagger}$ \\ Bacterial Interactions and Evolution Group, DTU Bioengineering, Technical University of Denmark, Kgs. Lyngby, Denmark
}

Accepted 27 September 2020.

\begin{abstract}
Bacillus subtilis is one of the most widely studied plant growth-promoting rhizobacteria. It is able to promote plant growth as well as control plant pathogens through diverse mechanisms, including the improvement of nutrient availability and alteration of phytohormone homeostasis as well as the production of antimicrobials and triggering induced systemic resistance, respectively. Even though its benefits for crop production have been recognized and studied extensively under laboratory conditions, the success of its application in fields varies immensely. It is widely accepted that agricultural application of $B$. subtilis often fails because the bacteria are not able to persist in the rhizosphere. Bacterial colonization of plant roots is a crucial step in the interaction between microbe and plant and seems, therefore, to be of great importance for its growth promotion and biocontrol effects. A successful root colonization depends thereby on both bacterial traits, motility and biofilm formation, as well as on a signal interplay with the plant. This review addresses current knowledge about plantmicrobial interactions of the $B$. subtilis species, including the various mechanisms for supporting plant growth as well as the necessity for the establishment of the relationship.
\end{abstract}

Keywords: Bacillus subtilis, biocontrol, biofilm, motility, plant growth promotion

Microorganisms are ubiquitous in nature. They are the base of the food chain, play a lead role in the carbon and nitrogen cycle and influence everyday life in various harmful as well as beneficial ways. Indeed, the continuous development and improvement of novel molecular tools and DNA sequencing techniques improved our understanding of the relationship between us and our microbiome immensely. Recent studies imply that the interactions with microbes contribute to a healthy development and disruption in the core microbiome can lead to drastic health issues (Bull and Plummer 2014;

Conclusions or recommendations expressed in this material are those of the authors and do not necessarily reflect the views of the Foundation.

${ }^{\dagger}$ Corresponding author: Á. T. Kovács; atkovacs@dtu.dk

Funding: This work was supported by funding from the Novo Nordisk Foundation via the project INTERACT (grant number NNF19SA0059360).

The author(s) declare no conflict of interest. license by waiving all of his or her rights to the work worldwide under copyright law, including all related and neighboring rights, to the extent allowed by law.
Nagalingam and Lynch 2012; Qin et al. 2012). In contrast, the importance of interactions between microbes and plants has been recognized long before that. The discovery that the soil surrounding plant roots, termed the rhizosphere, is much richer in bacteria than the surrounding bulk soil, sparked plant-microbial research (Hiltner 1904). Since then, numerous discoveries revealed that plants not only depend on symbiosis with bacteria, e.g., nitrogen-fixing bacteria, but some bacterial species are also able to enhance the yield of important crops, such as soybean and corn, or reduce the severity of plant diseases (Baker and Cook 1974; Kloepper and Schroth 1981). Such bacteria, which were termed plant growth-promoting rhizobacteria (PGPR), flourish in the rhizosphere, colonize roots, and aid plants in various ways (Lugtenberg and Kamilova 2009). In general, PGPR are able to improve nutrient availability, reduce abiotic stresses, such as lack or surplus of water or salts, increase plant defenses, and help to fight off pathogens (Bhattacharyya and Jha 2012). These diverse capabilities of PGPR as well as a few key advantages over traditionally used agrochemicals quickly led to the idea of developing biological products for agricultural applications. First of all, the diverse modes of action against pathogens of biocontrol agents, as compared with traditional pesticides, have long been thought to be able to slow down the evolution of resistant pathogens, even though this is still debatable (Bardin et al. 2015). Secondly, application of biological products, such as PGPR, are often regarded as more environment friendly, while, on the contrary, the excessive use of agrochemicals throughout several decades and its concomitant spread into the environment have caused significant contamination of natural systems (Carvalho 2017; PérezGarcía et al. 2011). In this review, we highlight various molecular aspects of how the commercially widely used PGPR Bacillus subtilis interacts with the plant.

\section{B. SUBTILIS, A PGPR}

B. subtilis is one of the most widely used and studied PGPR and a highly promising candidate for agricultural applications (Earl et al. 2008; Todorova and Kozhuharova 2010). Genus Bacillus is one of the most abundantly isolated genera in the soil, among which $B$. subtilis has been identified from the rhizosphere of distinct plants (Earl et al. 2008; Sivasakthi et al. 2014). It is a gram-positive, nonpathogenic bacterium that has been used as a model organism to study secondary metabolite production, sporulation, biofilm development, attachment to plant roots, and more (Fig. 1A) (Kovács 2019). Apart from its various benefits toward plant health, its ability to form resilient spores makes it a promising target for agricultural application. Spores are highly resistant to various abiotic stresses, such as drought, temperature, or nutrient limitation, making the formulation 
of B. subtilis easy (Schisler et al. 2004). The beneficial properties of B. subtilis are already exploited in many currently available biological products, including Serenade, Subtilex, and Cease (Borriss 2015).

Especially nowadays, when sustainability is increasingly emphasized and the rapid emergence of resistant plant pathogens exceeds the pace of pesticide discovery, the potential of biological products in agriculture seems immense (Fisher et al. 2018; Verma et al. 2019). However, even though biological products have been developed and applied for more than 50 years, agriculture still depends on traditional chemical methods. How can this be? Even though many studies prove the success of biologicals under controlled greenhouse conditions, the beneficial effects in the field seem to vary immensely (Bardin et al. 2015; Maplestone and Campbell 1989; Moreira and De Mio 2015; Xu et al. 2011). Inoculation of canola by a commercially used $B$. subtilis strain to control clubroot caused by Plasmodiophora brassicae has been proven to be highly efficient under controlled conditions, reducing disease severity by more than $80 \%$ (Peng et al. 2011). However, under open field conditions no substantial impact of the treatment has been observed (Peng et al. 2011). Similar results have been reported for the application of $B$. subtilis on strawberry leaves; after 8 days, the abundance of the biocontrol agent decreased by around $50 \%$ in the field, while no such decrease was observed under controlled conditions (Wei et al. 2016). The general accepted view of $B$. subtilis inoculants is that they are not able to persist on plants and in the rhizosphere if they are not introduced extensively (Shoda 2000). This demonstrates how complex plant-microbial interactions are, especially under noncontrolled conditions. A deeper understanding of the underlying mechanisms of this interplay might help improve the application in the field. Here, we address the current knowledge about plantmicrobial interactions of the $B$. subtilis species, including the diverse mechanisms for supporting plant growth as well as the necessities for the establishment of the relationship.

\section{PLANT GROWTH PROMOTION}

B. subtilis possesses many direct and indirect mechanisms to promote plant growth and, thus, crop yield, including improving nutrient availability, altering plant growth hormone homeostasis, and reducing severity of abiotic stresses (Fig. 1B).

\section{B. subtilis improves nutrient availability.}

Many important plant nutrients and trace elements, e.g., nitrogen, phosphorus, and iron, occur in the soil in an inaccessible form for plants and, thus, must be fixed or mobilized by rhizobacteria beforehand (Hayat et al. 2010). Plants are, for example, not able to use atmospheric nitrogen directly but depend on external help provided by microbial symbionts. $B$. subtilis is known to fix atmospheric nitrogen as well as promote nodulation by other bacteria and, thereby, improve the colonization of native symbiotic rhizobacteria (Elkoca et al. 2007). Another essential nutrient, which must be mobilized before it can be utilized by plants, is phosphorus. B. subtilis is able to solubilize phosphorus through the production of various organic acids that convert it into a soluble form (Saeid et al. 2018). Furthermore, metal ions, such as iron, are often a limiting factor for plant growth. Studies have shown that $B$. subtilis increases the content of iron in plants by facilitating iron mobility through acidification of the rhizosphere and by inducing the upregulation of iron acquisition genes in plants (Freitas et al. 2015; Zhang et al. 2009).

\section{B. subtilis alters plant growth hormone homeostasis.}

In addition to mobilizing nutrients, $B$. subtilis produces a wide range of compounds that directly influence plant growth in various ways. First of all, B. subtilis is able to actively alter plant growth hormone homeostasis and thus promotes cell division and plant growth, either through producing plant growth hormones themselves or by inducing
A

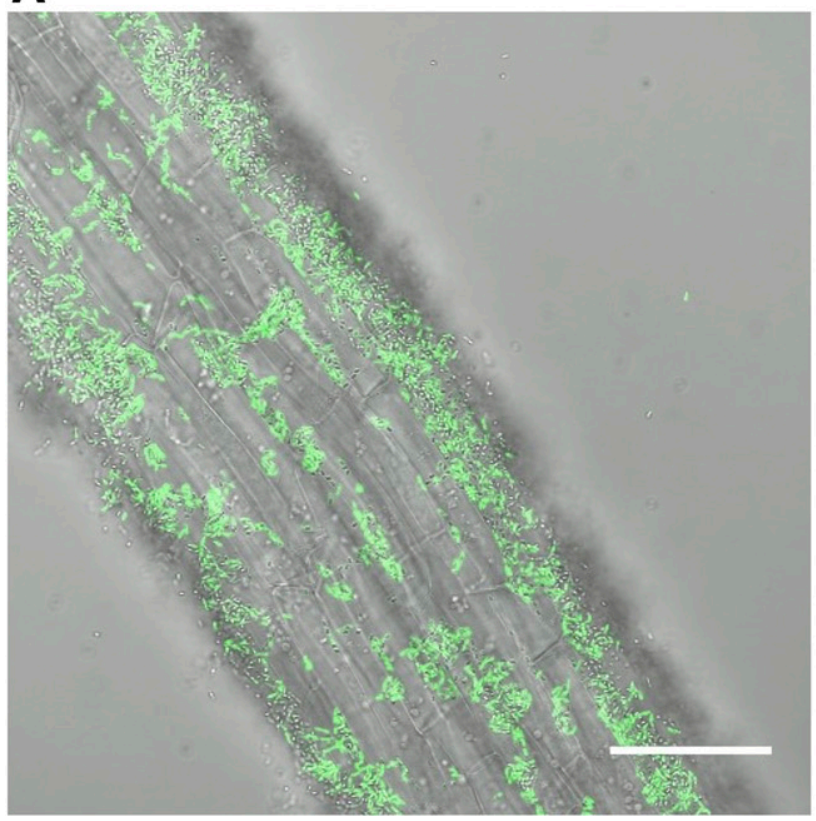

B

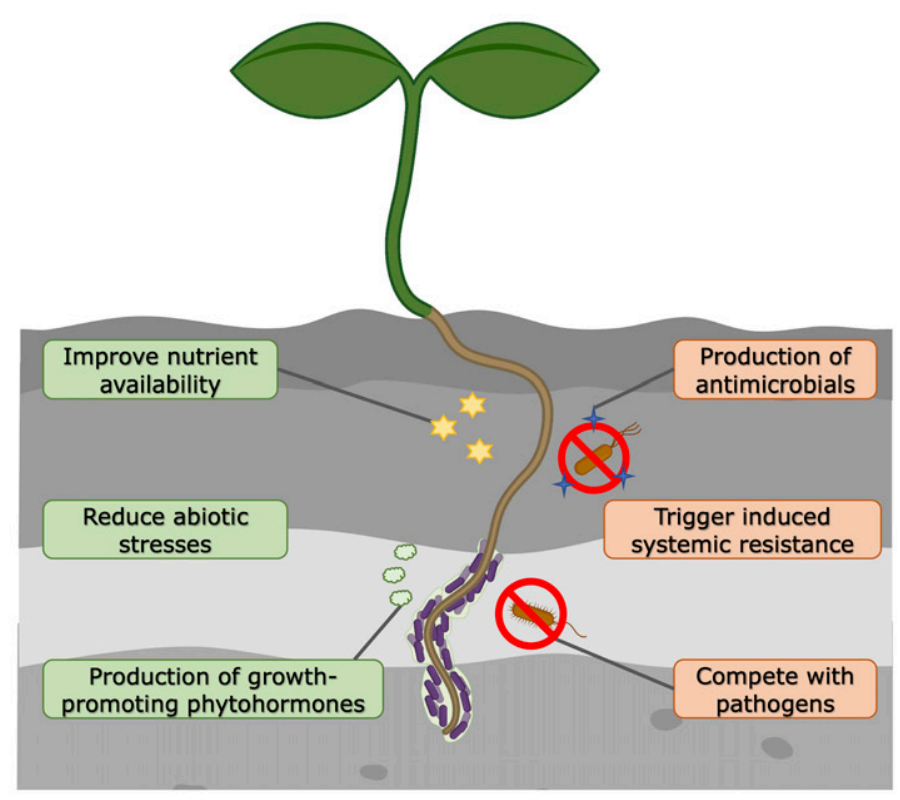

Fig. 1. Bacillus subtilis plant root colonization. A, Confocal microscopy image of green fluorescent protein-labeled B. subtilis cells on Arabidopsis thaliana root. The scale bar represents $50 \mu \mathrm{m}$. B, B. subtilis harbors multiple plant growth-promoting effects, including improvement of nutrient availability, reduction of abiotic stresses, and production of growth-promoting phytohormones as well as biocontrol properties, e.g., via production of antimicrobials, triggering induced systemic resistance, and competing with pathogens. Part of section B was created with BioRender. 
the production in plants through secreted compounds (Arkhipova et al. 2005).

Two volatile organic compounds produced by B. subtilis, namely 3-hydroxy-2-butanone (acetoin) and 2,3-butanediol, have been demonstrated to promote plant growth by altering cytokinin and ethylene homeostasis. Either inoculation with the producing $B$. subtilis strains or the application of the pure 2,3butanediol led to a significant increase in leaf size of wild-type Arabidopsis thaliana, whereas the GB03 strain failed to promote such a response in the cytokinin- and ethylene-insensitive mutants cre 1 and ein2 (Ryu et al. 2003). Furthermore, Zhang et al. (2007) showed that a blend of B. subtilis volatiles is able to regulate auxin homeostasis in A. thaliana, leading to lower levels of auxin in leaves but higher levels in roots. Because auxin inhibits leaf expansion but promotes root development, this redistribution might be able to promote optimal plant growth. Additionally, spermidine, a polyamine produced by $B$. subtilis, improves plant growth through the induction of expansins and reduction of ethylene levels in plants (Xie et al. 2014). Both inoculation with producing strains as well as the synthetic compound significantly improved root development (Xie et al. 2014).

In addition to such signaling molecules that indirectly affect hormone homeostasis, $B$. subtilis is known to be able to produce phytohormones itself. Arkhipova et al. (2005) observed that inoculation with a cytokinin-producing $B$. subtilis strain led to significantly increased accumulation of cytokinin in lettuce plants, which resulted in improved growth and yield. Such a growth-promoting effect is due to root absorption of B. subtilisproduced cytokinin and is not due to improved nutrient availability, as demonstrated by the accumulation of the hormone, which was higher in the roots of treated plants than in the shoot (Arkhipova et al. 2005).

\section{B. subtilis reduces abiotic stress.}

In addition to directly promoting plant growth, B. subtilis is able to reduce abiotic stresses that otherwise limit optimal crop yield. Water and salt stress are two major constraints for modern agriculture. Indeed, drought is already one of the most stressful environmental factors affecting crop yield worldwide and might even intensify through climate change in the near future ( $\mathrm{Li}$ et al. 2009). Fresh water is a limited resource and irrigation of crops might need to be reduced in the decades to come. Furthermore, prolonged irrigation leads to soil salinization and, up to now, around 20 to $50 \%$ of the irrigated cropland is already contaminated by salt (Fita et al. 2015).

B. subtilis has been reported to be able to increase plant tolerance against both drought and salt stress. Woo et al. (2020) recently showed that inoculation with $B$. subtilis GOT9 confers enhanced tolerance to drought and salt stress in A. thaliana and Brassica campestris via modulation of plant gene expression, including the upregulation of biosynthesis genes for abscisic acid (ABA), one of the main plant hormones for stress regulation. In addition, Zhang et al. (2010) demonstrated that $B$. subtilis is also able to enhance osmotic stress independently of ABA levels in A. thaliana. In this case, B. subtilis was able to minimize the drought-caused damage through enhanced osmoprotectant biosynthesis in the plant and organ-specific regulation of the plant $\mathrm{Na}^{+}$importer HKT1 (Zhang et al. 2008, 2010).

\section{BIOCONTROL}

B. subtilis also has various direct and indirect ways to protect plants against pathogens, including the production of antimicrobials and inducing systemic resistance.

\section{Plant protection through antibiosis.}

PGPR are known to inhibit plant pathogens directly through antibiosis. B. subtilis produces various compounds with antimicrobial properties, including lipopeptides, exoenzymes, and volatile organic compounds (Wang et al. 2015). One of the most studied and characterized secondary metabolites of B. subtilis is surfactin, a cyclic lipopeptide that has many important but distinct functions, such as signaling activities and reduction of surface tension (Sansinenea and Ortiz 2011). Because of its amphiphilic nature, surfactin is able to disrupt cell membranes of other organisms by integrating into the lipid layers (Ongena and Jacques 2008). It has often been reported to be the active compound in B. subtilis biocontrol against various plant pathogens (Fan et al. 2017).

Bais et al. (2004) showed that mortality rates of A. thaliana infected with Pseudomonas syringae are significantly reduced after inoculation with a surfactin producing $B$. subtilis, but not by inoculation with a surfactin deficient mutant strain. In addition, they show that surfactin is able to inhibit $P$. syringae in liquid culture in biological relevant concentrations (Bais et al. 2004). Fan et al. (2017) observed that a surfactin producing B. subtilis 9407 shows both strong antibacterial activity against the plant pathogen Acidovorax citrulli in vitro as well as a very efficient biocontrol on melon seedlings in the greenhouse. In contrast, both abilities were lost in a nonproducing $\triangle \operatorname{srf} A B$ mutant, indicating the importance of surfactin in biocontrol (Fan et al. 2017). However, other noteworthy phenotypic changes have been reported in the surfactin-deficient mutants that might lower their biocontrol capacity. Furthermore, because the production of surfactin seems to be highly intertwined with the synthesis of other secondary metabolites with antimicrobial properties, the mutant strain might also lack other antimicrobials (Luo et al. 2015).

Most B. subtilis strains are able to produce multiple antimicrobials. Additionally, surfactin and bacillomycin act synergistically in controlling pathogens, and their biosynthetic pathways are at least partly intertwined (Luo et al. 2015). Luo et al. (2015) showed that $B$. subtilis mutants deficient in surfactin production did not synthesize bacillomycin, while the addition of exogenous surfactin restored its production. In addition, single mutants deficient in bacillomycin production show less control against the fungi Rhizoctonia solani compared with the wild type (WT), while the surfactin and double mutants fail completely.

Apart from lipopeptides, $B$. subtilis is able to control fungal phytopathogens through the production of exoenzymes that are able to degrade the fungal cell wall, including proteases and chitinases. Liu et al. (2011) identified a chitinase produced by $B$. subtilis as the main antifungal component. Inoculation of tomato seedlings with the chitinase-producing $B$. subtilis strain led to a significant reduction in the amount of diseased plants of around $20 \%$ and $35 \%$ in greenhouse and field trials, respectively (Liu et al. 2011).

Finally, Chen et al. (2008) reported that volatiles produced by B. subtilis were able to inhibit spore germination and hyphal growth of the phytopathogen Botrytis cinerea in a contactindependent manner on agar plates. However, whether volatiles also play a role in biocontrol in planta has yet to be confirmed.

\section{Signal interference.}

It has been suggested, that $B$. subtilis is able to reduce disease severity not only through inhibiting pathogen growth directly but, also, by reducing their virulence (Pan et al. 2008). The induction of virulence genes in many pathogens relies on quorum sensing (QS) signals as regulators, and thus interfering with the QS signals involved in inducing virulence genes might be a promising strategy to reduce disease 
severity (Helman and Chernin 2015). B. subtilis has been shown to produce an enzyme, AiiA, that is able to inactivate QS autoinducers. (Dong et al. 2000; Pan et al. 2008). Pan et al. (2008) reported that B. subtilis BS-1, encoding an AiiA enzyme, was able to reduce potato soft rot symptoms caused by Erwinia carotovora, a pathogen dependent on autoinducers for virulence. Furthermore, supernatant from $E$. coli expressing the aiiA gene attenuated soft rot symptoms by Erwinia carotovora, supporting the role of the AiiA enzyme in inactivating the QS signals responsible for virulence gene expression (Pan et al. 2008).

\section{Induced systemic resistance.}

Next to direct inhibition of pathogens, B. subtilis is able to boost plant defenses by eliciting induced systemic resistance (ISR), in which inoculation of the roots with beneficial bacteria enhances the defense capacity of the entire plant against various pathogens, as discussed in a review by Kloepper et al. (2004). Our review here focuses on the molecular traits of B. subtilis related to plant-beneficial effects but does not describe ISR in detail, as it has been reviewed before by Pieterse et al. (2014).

It has been shown that various compounds produced by B. subtilis are responsible for eliciting ISR. Ongena et al. (2007) reported that root inoculation with both naturally high surfactin- and fengycin-producing $B$. subtilis strains were able to reduce disease caused by Botrytis cinera in tomato and bean leaves. The fact that no B. subtilis cells were detected in the leaves indicates that disease reduction occurred through ISR. Furthermore, to verify the role of surfactin as an active signal, it was shown that a surfactin overproducing strain was able to significantly reduce disease symptoms, in contrast to the otherwise ineffective and poorly producing natural strain (Ongena et al. 2007). Cawoy et al. (2014) further confirmed the importance of surfactin by showing that defense inducing activity by $B$. subtilis strains strongly correlated with the amount of surfactin produced by the isolates.

Kumar et al. (2012) observed that inoculation with B. subtilis elicited ISR in $A$. thaliana by restricting foliar entry of the phytopathogen $P$. syringae pv. tomato DC3000 through stomata. Root colonization of $B$. subtilis caused a significant increase in ABA and salicylic acid levels, resulting in stomata closure and thereby blocking the infection by $P$. syringae (Kumar et al. 2012).

In addition to contact-dependent signals, volatile compounds have been identified to be able to trigger ISR. Ryu et al. (2004) found that by physically separating $A$. thaliana seedlings from the PGPR, airborne signals were able to significantly reduce the amount of symptomatic leaves upon infection with Erwinia carotovora. Furthermore, they observed that the volatile compounds act independently of signal transduction pathways, used by PGPR that make physical contact (Ryu et al. 2004).

\section{Competition for niches.}

In addition to plant protection through antibiosis and eliciting ISR of the plant, PGPR such as B. subtilis have been suggested to be able to control phytopathogens through direct competition for resources including nutrients and space on the plant surface, as one might expect for bacteria occupying the same niches (Lugtenberg and Kamilova 2009). However, so far, experimental proof of this theory is still lacking.

\section{B. SUBTILIS RESPONSES TO PLANT SIGNALS}

Interestingly, the potential of B. subtilis to promote plant growth and enhance plant defenses against pathogens seems to differ strongly between strains. Even though some compounds, especially those with a broad target range and multiple functions, such as surfactin, are commonly synthesized by B. subtilis strains, the production of others, such as subtilin, seems to be strain-specific (Stein 2005; Kiesewalter et al. 2020). This indicates that some compounds might confer an advantage to the producing $B$. subtilis strain in specific ecological niches and thereby help to adapt and optimize specific plant-microbe interactions (Mukherjee and Das 2005). Obviously, promoting plant growth and helping the plant to fight off pathogens is not a selfless deed by $B$. subtilis. Rather, the bacteria benefit from the interactions with the plant. Indeed, the PGPR rely on carbon sources provided by the plant in otherwise nutrient-poor soil and often act specifically on signals produced by the plant (Sasse et al. 2018). Plant root exudates not only serve as a nutrient source for PGPR but also as signaling molecules, which often establish the connection and initiate the colonization process (Beauregard 2015). Even though some beneficial plant-microbial interactions seem to be independent of direct physical contact, as in the case of volatile organic compounds, both the biocontrol and plant growth-promoting effects have been reported to rely strongly on the ability of PGPR to successfully attach to and colonize the host plant, especially under natural conditions (Chen et al. 2013). This indicates that a successful root colonization is fundamental for a healthy relationship between the PGPR and its host plant. In this context, certain microbial attributes have proven to be essential, including chemotaxis to sense and reach the plant root and biofilm formation for attachment and persistence on the root.

\section{Motility_chemotaxis and swarming.}

During the initial phase of root colonization, active and directed movement in the form of chemotaxis seems to be highly advantageous for PGPR to be able to establish themselves on the roots (Fig. 2) (Allard-Massicotte et al. 2016). Chemotaxis allows bacterial cells to sense changes in chemical gradients around them and move accordingly to a more favorable environment or away from toxins (Garrity and Ordal 1995). A chemotactic response is triggered when stimulating molecules bind to the corresponding chemoreceptor located on the surface of bacteria, causing downstream modification of the CheA kinase and of its response regulator CheY (Garrity and Ordal 1997; Walukiewicz et al. 2014). CheY in turn interacts with the flagellar motor by controlling the direction of the motor rotation and therefore the switch between swimming and tumbling (Bischoff et al. 1993; Ward et al. 2019). In the lack of an attractant bound to the cognate chemoreceptor, CheA will remain inactive and $\mathrm{CheY}$ unphosphorylated, rendering the flagellar motor in the default state of rotating clockwise, causing the cell to reorientate through tumbling. Upon binding of an attractant to the chemoreceptor, CheA is activated and in turn phosphorylates CheY, which will cause counterclockwise rotation of the flagellar rotor, generating straight swimming toward the attractant (Garrity and Ordal 1997; Rao et al. 2004). Therefore, chemotaxis is not directed movement strictly speaking, but rather, a form of a random biased walk. On the other hand, how B. subtilis responds to the encounter with a repellent is less studied. It has been suggested that repellents act directly on the membrane rather than through the CheA-CheY pathway, leading to an increase in the tumbling frequency (Ordal and Goldman 1976).

Allard-Massicotte et al. (2016) have demonstrated that multiple chemoreceptors of B. subtilis are involved in a response to root exudates. A $\Delta c h e A$ mutant, deficient in chemotaxis in general, and two nonmotile mutants, flagellar filament mutant $\Delta$ hag and flagellar motor mutant $\Delta$ motA, were not able to colonize $A$. thaliana roots after $4 \mathrm{~h}$, in contrast to the WT, indicating that chemotaxis is essential for root colonization. 
Furthermore, they tested various chemoreceptor mutants in the presence of extracted root exudates in capillary assays, showing that the chemoreceptors $\mathrm{McpB}, \mathrm{McpC}$, and, at least to some extent, TlpC are responsible for a response toward amino acids and sugars present in the exudates. Interestingly, they also identified a mutant that showed significantly higher attraction toward the exudates compared with the WT, indicating that the chemoreceptor McpA responds to a repellent molecule present in the exudates (Allard-Massicotte et al. 2016).

Studies have indicated that plants are able to use this mechanism of secreting root exudates to actively recruit desired PGPR. Rudrappa et al. (2008) showed that infection with the phytopathogen $P$. syringae induces the secretion of L-malic acid, which promoted root colonization by $B$. subtilis. In addition, they confirmed in capillary assays that, indeed, L-malic acid is able to trigger a chemotactic response in $B$. subtilis and might act as an attractant (Rudrappa et al. 2008).

Chemotactic response has been proposed to act exclusively toward root exudates produced by distinct plant species and bacteria might have evolved to respond specifically to their cooccurring host plant (Zhang et al. 2014). Indeed, Zhang et al. (2014) have shown that a B. subtilis strain isolated from banana rhizosphere and a $B$. amylolicefaciens strain isolated from cucumber rhizosphere colonize their original host plant more efficiently than the nonhost plant. They observed a higher chemotactic response of $B$. subtilis toward concentrated root exudates of banana compared with cucumber, which might explain the higher colonization on its original plant host (Zhang et al. 2014).

It must be noted, however, that most studies test the role of chemotaxis for root colonization in liquid medium. It is evident that swimming is the main mechanism of motility in liquid media, however whether this also applies to soil is debatable. In a natural soil system, swarming, during which a whole cluster of cells moves rapidly on a solid surface in the form of dynamic multicellular rafts (Kearns and Losick 2003), might be of greater importance (Gao et al. 2016). Contrary to chemotactic swimming motility, swarming is nondirectional and requires the production of surfactin, which reduces surface tension by forming a small film of water in which the cells swarm (Kearns and Losick 2003). Gao et al. (2016) observed that cheA mutants, which are often used for chemotaxis studies, are also impaired in swarming and hypothesized that swarming might play an even greater role in root colonization than chemotaxis. Therefore, they tested a mutant that is only impaired in chemotaxis, cheV, as well as three mutants deficient in swarming, namely $\operatorname{srf} A C$, which is deficient in surfactin production, $s w r A$, and minJ, which are each missing one of the two genes of the swarming operon. Indeed, they showed that the chemotactic mutant is able to colonize $80 \%$ as efficiently as the WT, while the swarming mutants only showed 5 to $15 \%$ as many colonizing cells (Gao et al. 2016). However, it must be noted that lack of surfactin might additionally impact root colonization. In addition, both the swrA and minJ mutants showed highly elongated cells and might therefore harbor other negative side effects. Due to the methodology applied in this study, i.e., freshly germinated seeds were inoculated in a bacterial suspension for just a short time $(20 \mathrm{~min})$ compared with the incubation time after planting in a gnotobiotic system (14 days), differences in persistence and biofilm formation on the roots might mask the effect of swarming and chemotaxis. Therefore, further experiments should be carried out to test the importance of swarming for root colonization. In addition, what role the different modes of motility in general play in a natural soil system needs to be addressed.

\section{Biofilm formation.}

Apart from motility, the ability to form a stable biofilm for attachment and persistence on the plant root has been proven to be highly advantageous (Chen et al. 2013). Biofilms are one of the most successful forms of life and are found in a wide range of environments (Flemming et al. 2016). They consist of cells, which are packed tightly together, embedded in a self-produced

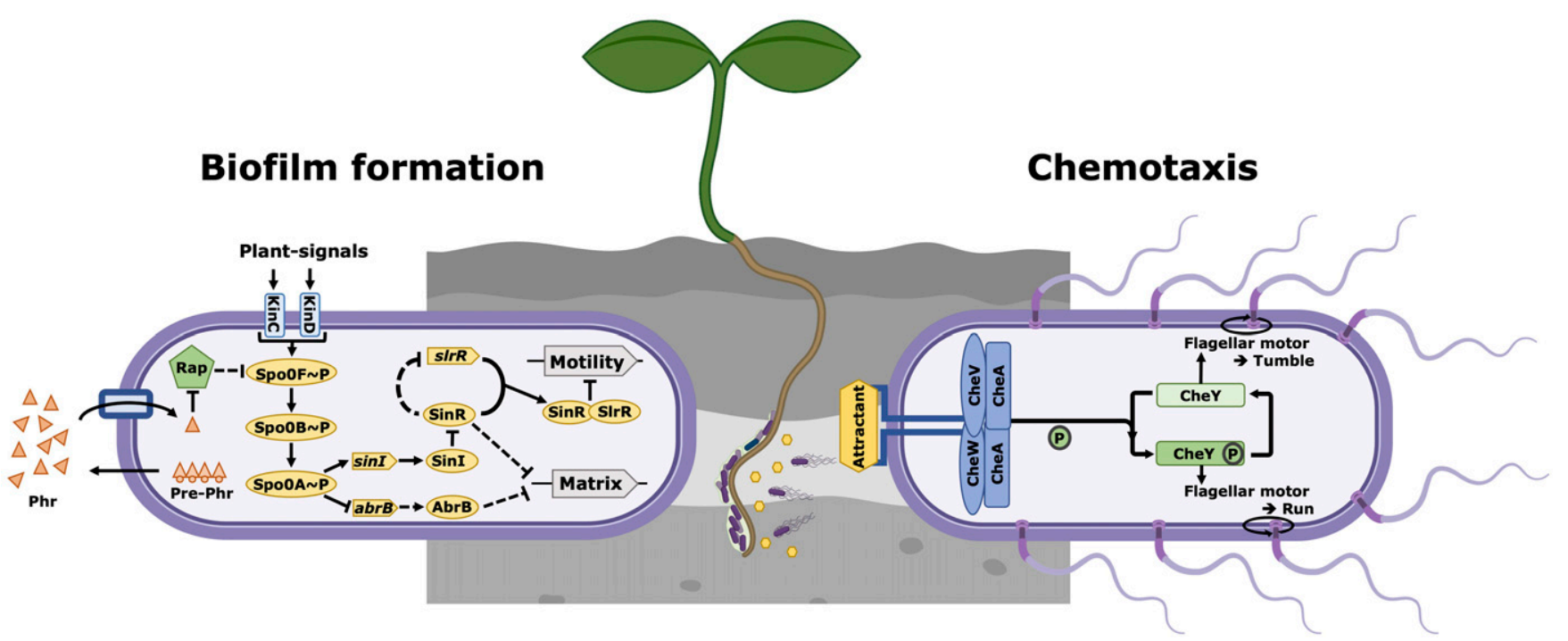

Fig. 2. Root colonization of Bacillus subtilis, biofilm formation, and chemotaxis. During chemotaxis, cells recognize the gradient of root exudates that act as attractants and move accordingly toward the root. Upon recognition and binding of root exudates by the chemoreceptor CheW/CheV, the kinase Che $\mathrm{A}$ gets activated, leading to the phosphorylation of its response regulator CheY. CheY in turn interacts with the flagellar motor, leading to a run if phosphorylated or a tumble if unphosphorylated. Once bacterial cells reach the root, the switch from single motile cells to biofilm formation regulated by the Spo0A pathway is essential. This switch is initiated by the recognition of plant signals via the sensor kinases KinCD, leading to a phosphorylation cascade involving SpoOF, Spo0B, and eventually Spo0A. Once phosphorylated, Spo0A P induces the production of SinI, which represses SinR and, thus, leading to derepression slrR. The expressed SlrR forms a complex with SinR, keeping the levels of free SinR low and, thus, derepresses matrix genes. In addition, the formed SlrR-SinR complex represses the expression of the motility gene hag and the autolysin genes $l y t A B C$ and $l y t F$, resulting thereby in sessile, coherent matrix-producing chains of cells. Furthermore, Spo0A P inhibits a second matrix repressor, AbrB, thereby relieving the repression of matrix genes. Part of this figure was created with BioRender. 
extracellular matrix (ECM), which in B. subtilis is composed mainly of an exopolysaccharide (EPS) and the protein TasA (Branda et al. 2006). Dragoš et al. (2018) have shown that both EPS and TasA are essential for a successful root colonization. They report that the number of cells colonizing the root is reduced for both null mutants $\Delta e p s$ and $\triangle t a s A$, as compared with the WT. Interestingly, when both mutants were inoculated at the roots in a mixture, the ability to form a stable biofilm was restored and the number of colonizing cells was, in fact, significantly higher compared with the WT, indicating that cells are able to share resources and division of labor occurs in B. subtilis biofilms on plant roots (Dragoš et al. 2018). Indeed, mature B. subtilis biofilms are known to be quite heterogeneous, and many different phenotypes apart from matrix producers can be present even in monospecies communities, including competent, cannibal, mining, motile, as well as sporulating cells (Abee et al. 2011; Mielich-Süss and Lopez 2015). This specification in performing different tasks allows division of labor, thereby assuring efficient resource utilization, which benefits the whole community (van Gestel et al. 2015). In $B$. subtilis, three master regulators have been identified as key players in controlling cell differentiation, namely DegU for exoprotease secretion, ComA for competence and surfactin production, and Spo0A for matrix production and, eventually, spore formation (Dahl et al. 1992; Hamon and Lazazzera 2001; Kunst et al. 1994; Mielich-Süss and Lopez 2015). They are activated upon phosphorylation by their corresponding kinases, which respond to specific external cues, including specific nutrients as well as signals from hosts, competitors, or cooperators (Beauregard et al. 2013; Burbulys et al. 1991; Dragoš et al. 2018; Oliveira et al. 2015). All three master regulators play a role in root colonization, at least to some extent.

The switch from motility to biofilm formation is mainly initiated by the expression of SinI, which is induced at intermediate levels of SpoOA $\sim \mathrm{P}$ (Fig. 2). Indeed, Beauregard et al. (2013) showed that both deletion in the master regulator Spo0A and the matrix derepressor SinI led to the inability of $B$. subtilis to colonize A. thaliana roots. Spo0A controls the repression of either matrix or motility genes through a doublenegative feedback loop between SlrR and SinR (Vlamakis et al. 2013). If Spo0A is unphosphorylated, $\sin I$ is not expressed and SinR represses slrR, keeping the levels of SlrR low, which enables SinR to repress matrix genes, e.g., eps and tasA (Kearns et al. 2005). At intermediate levels of Spo0A $\sim \mathrm{P}$, this response regulator binds to the high affinity activator site of sinI, activating the expression of SinI, which in turn binds to and inhibits SinR resulting in derepression of $\operatorname{slrR}$ (Chai et al. 2008; Chu et al. 2008). By forming a complex with SinR, the expressed SlrR inhibits SinR, resulting in sustained SlrR expression. In this high-SlrR state, the formation of SlrR-SinR complexes results in low levels of free $\operatorname{SinR}$ and, thus, derepression of matrix genes. In addition, the formed SlrR-SinR complex represses the expression of the motility gene hag and the autolysin genes lyt $A B C$ and $l y t F$, resulting, thereby, in sessile, coherent matrix-producing chains of cells (Bai et al. 1993; Chai et al. 2010; Chu et al. 2008). As the phosphorylation level of Spo0A $\sim \mathrm{P}$ increases, other low-affinity operators of $\sin I$ are bound and further production of SinI is reduced, while at the same time sporulation genes are activated (Fujita et al. 2005). In addition, an alternative matrix gene repressor AbrB, which also targets eps and tasA as well as blsA, encoding for a surface hydrophobicity protein, is connected to the Spo0A pathway, enabling further fine tuning of the expression of matrix-related genes (Chu et al. 2008; Vlamakis et al. 2013). AbrB will be expressed at low Spo0A $\sim \mathrm{P}$ levels and represses matrix genes, while an intermediate level of $\mathrm{Spo} 0 \mathrm{~A} \sim \mathrm{P}$ causes repression of the $a b r B$ gene while inducing expression of AbbA, which inhibits the AbrB present in the cell and thereby relieving the repression of matrix genes (Banse et al. 2008).

Chen et al. (2013) confirmed that, indeed, the same core regulatory genes known to be essential for in vitro biofilm formation in B. subtilis are also essential for efficient root colonization and the biocontrol effect against Ralstonia solanacearum on tomato plants. Various null mutations within the Spo0A pathways led to either hyper-robust biofilms with a higher number of cells colonizing $(\triangle a b r B$ and $\Delta \sin R)$ or defective biofilms with a decreased number of cells attached to the root $(\Delta \sin I, \Delta e p s$, and $\Delta \operatorname{tas} A)$, depending on whether they negatively or positively impact biofilm development, respectively (Chen et al. 2013).

Until now, five different kinases, KinA through KinE, that trigger the phosphorylation cascade of Spo0A in response to different signals have been identified (Jiang et al. 2000b). KinC and KinD have been identified to be directly involved in root colonization by initiating biofilm formation upon various signals from the host plant. Chen et al. (2012) reported that a $\Delta$ kinD mutant was not able to form a biofilm on tomato roots. They identified L-malic acid as the responsible signal for biofilm induction, however, because the concentrations needed for biofilm formation were quite high, they suspected that L-malic acid might primarily function as the carbon source, which alters metabolism in favor of biofilm lifestyle (Chen et al. 2012). Furthermore, Shemesh and Chai (2013) showed that a combination of glycerol, one of the main root exudates, and manganese strongly promoted pellicle formation. However, the effect was significantly reduced for a $\Delta k i n D$ and less for the $\Delta k i n C$ mutant, further indicating the importance of these kinases in biofilm formation toward plant related signals (Shemesh and Chai 2013). Adding to the evidence of KinC and KinD being involved in biofilm formation in response to root exudates, Beauregard et al. (2013) observed that the plant polysaccharides arabinogalactan, pectin, and xylan induced pellicle formation of $B$. subtilis. They tested the ability of mutants deficient in one of the five kinases, KinA through KinE, as well as the double mutant $\triangle$ kinCD to form a pellicle in response to the three plant polysaccharides, identifying KinC and KinD as responsible sensors for pectin and arabinogalactan. However, all mutants were still able to form a biofilm in response to xylan, indicating that an additional yet-unidentified pathway is able to trigger biofilm formation in response to plant signals. In addition, they have identified over 40 predicted glycosyl hydrolases in B. subtilis that could digest plant polysaccharides, allowing them to be used as carbon source for cell growth and other metabolic processes. Indeed, they show that B. subtilis utilizes plant polysaccharides to incorporate them into matrix EPS (Beauregard et al. 2013).

In addition to Spo0A, DegU plays an important role in regulating the switch from motile to biofilm state in B. subtilis by repressing motility genes in its phosphorylated form (Kobayashi 2007; Verhamme et al. 2007). It also regulates the production of the surface hydrophobicity protein BslA and poly- $\gamma$-glutamic acids (PGA), which are essential for a stable biofilm (Marlow et al. 2014; Yu et al. 2016). Indeed, Yu et al. (2016) observed that root colonization efficiency positively correlated with $\gamma$-PGA production in strong producing $B$. subtilis strains. Even though a direct link between root colonization and DegU has not yet been shown for $B$. subtilis, a $\Delta \operatorname{deg} U$ mutant of the close relative $B$. amyloliquefaciens was not able to colonize A. thalina roots compared with the WT, indicating that DegU might be critical for root colonization (Dietel et al. 2013).

The final master regulator ComA impacts root colonization to some extent by indirectly influencing biofilm formation. Next to competence, ComA regulates the production of surfactin (Nakano and Zuber 1991). Surfactin has been thought to 
be an essential signaling molecule stimulating biofilm formation in B. subtilis by inducing potassium leakage (López et al. 2009). López et al. (2009) observed that mutants deficient in surfactin production were also impaired in biofilm formation. However, Thérien et al. (2020) recently reported that this holds true only under nonbiofilm-inducing conditions, while, in biofilm-inducing media MSgg and $\mathrm{MSNg}$, B. subtilis was able to create a stable biofilm independent of surfactin. Furthermore, they observed no difference in the root colonization capacity of a mutant deficient in surfactin production ( $s r f A A)$, compared with the WT, indicating that surfactin is not required for root colonization (Thérien et al. 2020).

To further fine-tune cell differentiation, all three master regulators are additionally controlled through QS (Omer Bendori et al. 2015). QS enables cell-to-cell communication on the basis of the production, secretion, and response to an autoinducer (Fuqua et al. 1994). This allows cells to detect the cellular density of other producers and, thereby, potential cooperators around them and to respond accordingly. This is a key requirement for the development of cooperative behavior because it stabilizes the production of public goods, such as surfactin or ECM components (von Bodman et al. 2008). In B. subtilis, phosphatase regulator (Phr) peptides and their cognate response regulator aspartyl-phosphate (Rap) phosphatases evoke QS, which controls the activity of the three master regulators (Omer Bendori et al. 2015). The autoinducer Phr is translated as pre-Phr proteins that are secreted and processed into mature Phr peptides (Pottathil and Lazazzera 2003). At a high cell density, the Phr peptides will reach a threshold concentration allowing them to be imported into the cell, where they will bind to and inhibit their cognate Rap phosphatase, relieving the inhibition of the master regulator and thus resulting in changed expression of target genes (Pottathil and Lazazzera 2003). Spo0A is controlled by RapABEHIJ60, as they inhibit the phosphorylation of Spo0A through dephosphorylating SpoOF $\sim \mathrm{P}$, while Rap phosphatases regulate ComA (RapCDFGHKPQ60) and DegU (RapG), mainly by preventing their DNA-binding activity (Boguslawski et al. 2015; Core and Perego 2003; Gallego del Sol and Marina 2013; Diaz et al. 2012; Hayashi et al. 2006; Jiang et al. 2000a; Ogura and Fujita 2007; Parashar et al. 2011, 2013; Perego 2013; Yang et al. 2015). To what extent QS plays a role in B. subtilis root colonization is yet unknown.

Apart from the QS autoinducer Phr and the secondary metabolite surfactin, B. subtilis produces and secretes cyclic diadenylate monophosphate, which might act as signal during biofilm formation. Townsley et al. (2018) reported that c-diAMP acts as an extracellular signaling molecule to impact biofilm formation and root colonization, which might be due to alterations in the phosphorylation state of Spo0A. However, the exact molecular mechanism has yet to be identified.

\section{B. subtilis modifies plant cell-wall and defense mechanisms to improve colonization.}

The signaling responsible for inducing biofilm formation on the root is not unidirectional from plant to microbe but, rather, an interplay between them. In addition to plant-produced compounds that trigger a chemotactic response and biofilm formation in bacterial cells, $B$. subtilis is able to influence gene expression in plants, which promotes root colonization. Lakshmanan and Bais (2013) observed that around 300 genes were differently expressed in A. thaliana, when colonized by $B$. subtilis. This included downregulation of genes related to defense signaling in roots as well as downregulation of cell wall-related genes, which might facilitate both initial attachment and survivability and, thus, overall root colonization
(Lakshmanan and Bais 2013). Indeed, downregulation of genes involved in the innate immune response of the plant might play an important role during establishment of B. subtilis on the root, as it might help bacterial cells to evade the plant defense mechanisms during initial colonization (Rekha et al. 2018). Various compounds produced by B. subtilis, including lipopetides such as surfactins and iturins as well as essential bacterial components, e.g., flagellin, act as microbe-associated molecular patterns, which trigger certain immune responses in the plant (Farace et al. 2015). Rekha et al. (2018) observed that $B$. subtilis RR4 suppresses various immune-related genes initially during colonization of rice roots, thereby facilitating its own colonization while it induces defense responses gradually at a later stage to boost plant immunity. Another mechanism to evade plant innate immune responses has been observed by Deng et al. (2019), who described how the endophytic B. subtilis BSn5 is able to mask self-produced flagellin through the production of lantibiotic subtilomycin, thereby reducing stimulation of the plant defense response.

Furthermore, Kerff et al. (2008) identified a protein, EXLX1, that is produced and secreted by $B$. subtilis that seems important for plant-microbial interactions. It has a very similar structure to that of plant $\beta$-expansin and was able to bind to plant cell walls and promoted their extension. In addition, they show that mutants deficient in EXLX1 production also showed significantly decreased root colonization compared with the WT (Kerff et al. 2008).

\section{B. subtilis colonizes roots in a kin-discriminated manner.}

Just as distinct $B$. subtilis strains vary in their ability to promote plant growth and control phytopathogens, so do they vary in their ability to successfully colonize plant roots. Interestingly, the genetic relatedness between different $B$. subtilis strains impacts their ability to co-colonize a plant root or competitively exclude one another. Stefanic et al. (2015) observed that, after inoculating A. thaliana roots with pairs of nonkin strains, the biofilm on the root mostly consisted of only one strain, implicating antagonistic interactions between the two strains. However, inoculation with a pair of kin strains resulted in mixed biofilms and co-colonization, implying that B. subtilis colonizes plant roots in a kin-discriminated manner (Stefanic et al. 2015).

\section{The role of the natural plant microbiome.}

It must be emphasized that most studies analyzing root colonization of B. subtilis have been conducted under sterile and highly controlled conditions. Obviously, this is far from the natural, complex environment for B. subtilis, i.e., the rhizosphere and plant root, and observations from the laboratory is often hard to reproduce under field conditions. The rhizosphere has been shown to harbor up to $10^{11}$ microbial cells per gram, representing more than 30,000 species (Berendsen et al. 2012). One cause of the variability in the success of biocontrol under field conditions might be the naturally occurring plant microbiomes. Interactions between microbes can be both cooperative or competitive, meaning that, depending on co-occurring bacteria, root colonization by $B$. subtilis might be improved or reduced or, even, successful or unsuccessful. For example, Pseudomonas protegens, another widely used PGPR, is able to inhibit biofilm formation of $B$. subtilis in coculture by producing a compound, namely 2,4-diacetylphloroglucinol, that delays cell differentiation by repressing biofilm-specific genes (Powers et al. 2015). Accordingly, biofilm formation not only plays an important role in root colonization per se, but it also modulates the interaction with co-occurring microbes. Indeed, Molina-Santiago et al. (2019) observed that a B. subtilis $\Delta$ matrix mutant, deficient in the production of biofilm matrix, 
show a higher sensibility toward invasion of Pseudomonas chlororaphis, leading to higher sporulation in coinoculation of melon seeds. On the other hand, coinoculation of B. subtilis and $B$. licheniformis improved plant growth of red pepper and tomato synergistically, indicating a positive interaction between the pair (Lim and Kim 2009).

The addition of $B$. subtilis to a natural rhizosphere has been shown to have only minor effects on the overall plant microbiome. Qiao et al. (2017) reported that inoculating tomato plants with $B$. subtilis in a greenhouse study had an impact on the eukaryotic community that lasted 14 days, while the bacterial community was only affected for 3 days. Wei et al. (2016) observed a similar result, but for application of $B$. subtilis on leaves rather than by root inoculation. Here, B. subtilis also seemed to have only minor effects on the natural phyllosphere microbiome (Wei et al. 2016). However, what effect the natural plant microbiome has on $B$. subtilis and if specific taxa might be able to improve its root colonization is not known and should be investigated further.

\section{Outlook.}

Even though our understanding of how B. subtilis colonizes and interacts with plants has improved immensely over recent decades, there are still numerous questions that need to be addressed. Especially transition from testing various natural and laboratory B. subtilis strains under highly controlled conditions toward testing under natural soil systems needs to be advanced further. This means, on the one hand, we need to determine the extent of correlation between observations in laboratory settings with natural conditions, e.g., the importance of biofilm formation and chemotaxis during colonization. On the other hand, we need to discover what role the natural microbiome of the plant and co-occurring microbes in the soil play. The assembly of the plant microbiome is among other things governed by the complex interactions among the microorganisms (Trivedi et al. 2020). Indeed, it has been shown that synergistic interactions and coculturing of multispecies biofilm of Pseudomonas spp. and Bacillus spp. (relatives of B. subtilis) on banana roots influence the assembly of the community at the root-microbiome interface and act as a plantbeneficial consortium against pathogens (Tao et al. 2020). This must also be addressed for $B$. subtilis in order to identify how distinct PGPR interact with $B$. subtilis in a consortium, whether they might facilitate $B$. subtilis root colonization and, ultimately, if the microbial consortium including $B$. subtilis acts synergistically in protecting plants against pathogens. This knowledge will help us to greatly optimize the application of $B$. subtilis in agriculture in addition to learning about complex microbiomes.

\section{LITERATURE CITED}

Abee, T., Kovács, Á. T., Kuipers, O. P., and van der Veen, S. 2011. Biofilm formation and dispersal in gram-positive bacteria. Curr. Opin. Biotechnol. 22:172-179.

Allard-Massicotte, R., Tessier, L., Lécuyer, F., Lakshmanan, V., Lucier, J. F., Garneau, D., Caudwell, L., Vlamakis, H., Bais, H. P., and Beauregard, P. B. 2016. Bacillus subtilis early colonization of Arabidopsis thaliana roots involves multiple chemotaxis receptors. MBio 7:e01664-16.

Arkhipova, T. N., Veselov, S. U., Melentiev, A. I., Martynenko, E. V., and Kudoyarova, G. R. 2005. Ability of bacterium Bacillus subtilis to produce cytokinins and to influence the growth and endogenous hormone content of lettuce plants. Plant Soil 272:201-209.

Bai, U., Mandic-Mulec, I., and Smith, I. 1993. SinI modulates the activity of SinR, a developmental switch protein of Bacillus subtilis, by proteinprotein interaction. Genes Dev. 7:139-148.

Bais, H. P., Fall, R., and Vivanco, J. M. 2004. Biocontrol of Bacillus subtilis against infection of Arabidopsis roots by Pseudomonas syringae is facilitated by biofilm formation and surfactin production. Plant Physiol. 134:307-319.
Baker, K. F., and Cook, R. J. 1974. Biological Control of Plant Pathogens. WH Freeman and Company, San Francisco, CA, U.S.A.

Banse, A. V., Chastanet, A., Rahn-Lee, L., Hobbs, E. C., and Losick, R. 2008. Parallel pathways of repression and antirepression governing the transition to stationary phase in Bacillus subtilis. Proc. Natl. Acad. Sci. U.S.A. 105:15547-15552.

Bardin, M., Ajouz, S., Comby, M., Lopez-Ferber, M., Graillot, B., Siegwart, M., and Nicot, P. C. 2015. Is the efficacy of biological control against plant diseases likely to be more durable than that of chemical pesticides? Front. Plant Sci. 6:566.

Beauregard, P. B. 2015. Not just sweet talkers: How roots stimulate their colonization by beneficial bacteria. Adv. Bot. Res. 75:1-20.

Beauregard, P. B., Chai, Y., Vlamakis, H., Losick, R., and Kolter, R. 2013. Bacillus subtilis biofilm induction by plant polysaccharides. Proc. Natl. Acad. Sci. U.S.A. 110:E1621-E1630.

Berendsen, R. L., Pieterse, C. M., and Bakker, P. A. 2012. The rhizosphere microbiome and plant health. Trends Plant Sci. 17:478-486.

Bhattacharyya, P. N., and Jha, D. K. 2012. Plant growth-promoting rhizobacteria (PGPR): Emergence in agriculture. World J. Microbiol. Biotechnol. 28:1327-1350.

Bischoff, D. S., Bourret, R. B., Kirsch, M. L., and Ordal, G. W. 1993. Purification and characterization of Bacillus subtilis CheY. Biochemistry 32:9256-9261.

Boguslawski, K. M., Hill, P. A., and Griffith, K. L. 2015. Novel mechanisms of controlling the activities of the transcription factors Spo0A and ComA by the plasmid-encoded quorum sensing regulators Rap60-Phr60 in Bacillus subtilis. Mol. Microbiol. 96:325-348.

Borriss, R. 2015. Bacillus, a plant-beneficial bacterium. Pages 379-391 in: Principles of Plant-Microbe Interactions. Springer International Publishing, Leiden, The Netherlands.

Branda, S. S., Chu, F., Kearns, D. B., Losick, R., and Kolter, R. 2006. A major protein component of the Bacillus subtilis biofilm matrix. Mol. Microbiol. 59:1229-1238.

Bull, M. J., and Plummer, N. T. 2014. Part 1: The human gut microbiome in health and disease. Integr. Med. (Encinitas) 13:17-22.

Burbulys, D., Trach, K. A., and Hoch, J. A. 1991. Initiation of sporulation in B. subtilis is controlled by a multicomponent phosphorelay. Cell 64 545-552.

Carvalho, F. P. 2017. Pesticides, environment, and food safety. Food Energy Secur. 6:48-60.

Cawoy, H., Mariutto, M., Henry, G., Fisher, C., Vasilyeva, N., Thonart, P., Dommes, J., and Ongena, M. 2014. Plant defense stimulation by natural isolates of Bacillus depends on efficient surfactin production. Mol. Plant-Microbe Interact 27:87-100.

Chai, Y., Chu, F., Kolter, R., and Losick, R. 2008. Bistability and biofilm formation in Bacillus subtilis. Mol. Microbiol. 67:254-263.

Chai, Y., Norman, T., Kolter, R., and Losick, R. 2010. An epigenetic switch governing daughter cell separation in Bacillus subtilis. Genes Dev. 24: 754-765.

Chen, H., Xiao, X., Wang, J., Wu, L., Zheng, Z., and Yu, Z. 2008. Antagonistic effects of volatiles generated by Bacillus subtilis on spore germination and hyphal growth of the plant pathogen, Botrytis cinerea. Biotechnol. Lett. 30:919-923.

Chen, Y., Cao, S., Chai, Y., Clardy, J., Kolter, R., Guo, J. H., and Losick, R. 2012. A Bacillus subtilis sensor kinase involved in triggering biofilm formation on the roots of tomato plants. Mol. Microbiol. 85:418-430.

Chen, Y., Yan, F., Chai, Y., Liu, H., Kolter, R., Losick, R., and Guo, J. H. 2013. Biocontrol of tomato wilt disease by Bacillus subtilis isolates from natural environments depends on conserved genes mediating biofilm formation. Environ. Microbiol. 15:848-864.

Chu, F., Kearns, D. B., McLoon, A., Chai, Y., Kolter, R., and Losick, R. 2008. A novel regulatory protein governing biofilm formation in Bacillus subtilis. Mol. Microbiol. 68:1117-1127.

Core, L., and Perego, M. 2003. TPR-mediated interaction of RapC with ComA inhibits response regulator-DNA binding for competence development in Bacillus subtilis. Mol. Microbiol. 49:1509-1522.

Dahl, M. K., Msadek, T., Kunst, F., and Rapoport, G. 1992. The phosphorylation state of the DegU response regulator acts as a molecular switch allowing either degradative enzyme synthesis or expression of genetic competence in Bacillus subtilis. J. Biol. Chem. 267:14509-14514.

Deng, Y., Chen, H., Li, C., Xu, J., Qi, Q., Xu, Y., Zhu, Y., Zheng, J., Peng, D., Ruan, L., and Sun, M. 2019. Endophyte Bacillus subtilis evade plant defense by producing lantibiotic subtilomycin to mask self-produced flagellin. Commun. Biol. 2:368.

Diaz, A. R., Core, L. J., Jiang, M., Morelli, M., Chiang, C. H., Szurmant, H., and Perego, M. 2012. Bacillus subtilis RapA phosphatase domain interaction with its substrate, phosphorylated Spo0F, and its inhibitor, the PhrA peptide. J. Bacteriol. 194:1378-1388. 
Dietel, K., Beator, B., Budiharjo, A., Fan, B., and Borriss, R. 2013. Bacterial traits involved in colonization of Arabidopsis thaliana roots by Bacillus amyloliquefaciens FZB42. Plant Pathol. J. 29:59-66.

Dong, Y. H., Xu, J. L., Li, X. Z., and Zhang, L. H. 2000. AiiA, an enzyme that inactivates the acylhomoserine lactone quorum-sensing signal and attenuates the virulence of Erwinia carotovora. Proc. Natl. Acad. Sci. U.S.A. 97:3526-3531.

Dragoš, A., Kiesewalter, H., Martin, M., Hsu, C. Y., Hartmann, R., Wechsler, T., Eriksen, C., Brix, S., Drescher, K., Stanley-Wall, N., Kümmerli, R., and Kovács, Á. T. 2018. Division of labor during biofilm matrix production. Curr. Biol. 28:1903-1913.e5.

Earl, A. M., Losick, R., and Kolter, R. 2008. Ecology and genomics of Bacillus subtilis. Trends Microbiol. 16:269-275.

Elkoca, E., Kantar, F., and Sahin, F. 2007. Influence of nitrogen fixing and phosphorus solubilizing bacteria on the nodulation, plant growth, and yield of chickpea. J. Plant Nutr. 31:157-171.

Fan, H., Zhang, Z., Li, Y., Zhang, X., Duan, Y., and Wang, Q. 2017. Biocontrol of bacterial fruit blotch by Bacillus subtilis 9407 via surfactin-mediated antibacterial activity and colonization. Front. Microbiol. 8:1973.

Farace, G., Fernandez, O., Jacquens, L., Coutte, F., Krier, F., Jacques, P., Clément, C., Barka, E. A., Jacquard, C., and Dorey, S. 2015. Cyclic lipopeptides from Bacillus subtilis activate distinct patterns of defence responses in grapevine. Mol. Plant Pathol. 16:177-187.

Fisher, M. C., Hawkins, N. J., Sanglard, D., and Gurr, S. J. 2018. Worldwide emergence of resistance to antifungal drugs challenges human health and food security. Science 360:739-742.

Fita, A., Rodríguez-Burruezo, A., Boscaiu, M., Prohens, J., and Vicente, O. 2015. Breeding and domesticating crops adapted to drought and salinity: A new paradigm for increasing food production. Front. Plant Sci. 6:978.

Flemming, H. C., Wingender, J., Szewzyk, U., Steinberg, P., Rice, S. A., and Kjelleberg, S. 2016. Biofilms: An emergent form of bacterial life. Nat. Rev. Microbiol. 14:563-575.

Freitas, M. A., Medeiros, F. H., Carvalho, S. P., Guilherme, L. R., Teixeira W. D., Zhang, H., and Paré, P. W. 2015. Augmenting iron accumulation in cassava by the beneficial soil bacterium Bacillus subtilis (GBO3). Front. Plant Sci. 6:596.

Fujita, M., González-Pastor, J. E., and Losick, R. 2005. High- and lowthreshold genes in the Spo0A regulon of Bacillus subtilis. J. Bacteriol. 187:1357-1368.

Fuqua, W. C., Winans, S. C., and Greenberg, E. P. 1994. Quorum sensing in bacteria: The LuxR-LuxI family of cell density-responsive transcriptional regulators. J. Bacteriol. 176:269-275.

Gallego del Sol, F., and Marina, A. 2013. Structural basis of Rap phosphatase inhibition by Phr peptides. PLoS Biol. 11:e1001511.

Gao, S., Wu, H., Yu, X., Qian, L., and Gao, X. 2016. Swarming motility plays the major role in migration during tomato root colonization by Bacillus subtilis SWR01. Biol. Control 98:11-17.

Garrity, L. F., and Ordal, G. W. 1995. Chemotaxis in Bacillus subtilis: How bacteria monitor environmental signals. Pharmacol. Ther. 68:87-104.

Garrity, L. F., and Ordal, G. W. 1997. Activation of the CheA kinase by asparagine in Bacillus subtilis chemotaxis. Microbiol. Read. 143: 2945-2951.

Hamon, M. A., and Lazazzera, B. A. 2001. The sporulation transcription factor SpoOA is required for biofilm development in Bacillus subtilis. Mol. Microbiol. 42:1199-1209.

Hayashi, K., Kensuke, T., Kobayashi, K., Ogasawara, N., and Ogura, M. 2006. Bacillus subtilis $\mathrm{RghR}$ (YvaN) represses rapG and $\mathrm{rapH}$, which encode inhibitors of expression of the srfA operon. Mol. Microbiol. 59: 1714-1729.

Hayat, R., Ali, S., Amara, U., Khalid, R., and Ahmed, I. 2010. Soil beneficial bacteria and their role in plant growth promotion: A review. Ann. Microbiol. 60:579-598.

Helman, Y., and Chernin, L. 2015. Silencing the mob: Disrupting quorum sensing as a means to fight plant disease. Mol. Plant Pathol. 16:316-329.

Hiltner, L. 1904. Uber nevere Erfahrungen und Probleme auf dem Gebiet der Boden Bakteriologie und unter besonderer Beurchsichtigung der Grundungung und Broche. Arbeit. Deut. Landw. Ges. Berl. 98:59-78.

Jiang, M., Grau, R., and Perego, M. 2000a. Differential processing of propeptide inhibitors of Rap phosphatases in Bacillus subtilis. J. Bacteriol. 182:303-310

Jiang, M., Shao, W., Perego, M., and Hoch, J. A. 2000b. Multiple histidine kinases regulate entry into stationary phase and sporulation in Bacillus subtilis. Mol. Microbiol. 38:535-542.

Kearns, D. B., Chu, F., Branda, S. S., Kolter, R., and Losick, R. 2005. A master regulator for biofilm formation by Bacillus subtilis. Mol. Microbiol. 55:739-749.
Kearns, D. B., and Losick, R. 2003. Swarming motility in undomesticated Bacillus subtilis. Mol. Microbiol. 49:581-590.

Kerff, F., Amoroso, A., Herman, R., Sauvage, E., Petrella, S., Filée, P., Charlier, P., Joris, B., Tabuchi, A., Nikolaidis, N., and Cosgrove, D. J. 2008. Crystal structure and activity of Bacillus subtilis YoaJ (EXLX1), a bacterial expansin that promotes root colonization. Proc. Natl. Acad. Sci. U.S.A. 105:16876-16881.

Kiesewalter, H. T., Andrade, C. N. L., Wibowo, M., Strube, M. L., Maroti, G., Snyder, D., Jørgensen, T. S., Larsen, T. O., Cooper, V. S., Weber, T., and Kovács, Á. T. 2020. Genomic and chemical diversity of Bacillus subtilis secondary metabolites against plant pathogenic fungi. bioRxiv. doi: 10.1101/2020.08.05.238063

Kloepper, J. W., Ryu, C. M., and Zhang, S. 2004. Induced systemic resistance and promotion of plant growth by Bacillus spp. Phytopathology 94:1259-1266.

Kloepper, J. W., and Schroth, M. N. 1981. Relationship of in vitro antibiosis of plant growth-promoting rhizobacteria to plant growth and the displacement of root microflora. Phytopath. 71:1020-1024.

Kobayashi, K. 2007. Gradual activation of the response regulator DegU controls serial expression of genes for flagellum formation and biofilm formation in Bacillus subtilis. Mol. Microbiol. 66:395-409.

Kovács, A. T. 2019. Bacillus subtilis. Trends Microbiol. 27:724-725.

Kumar, A. S., Lakshmanan, V., Caplan, J. L., Powell, D., Czymmek, K. J., Levia, D. F., and Bais, H. P. 2012. Rhizobacteria Bacillus subtilis restricts foliar pathogen entry through stomata. Plant J. 72: 694-706.

Kunst, F., Msadek, T., Bignon, J., and Rapoport, G. 1994. The DegS/DegU and ComP/ComA two-component systems are part of a network controlling degradative enzyme synthesis and competence in Bacillus subtilis. Res. Microbiol. 145:393-402.

Lakshmanan, V., and Bais, H. P. 2013. Factors other than root secreted malic acid that contributes toward Bacillus subtilis FB17 colonization on Arabidopsis roots. Plant Signal. Behav. 8:e27277.

Li, Y., Ye, W., Wang, M., and Yan, X. 2009. Climate change and drought: A risk assessment of crop-yield impacts. Clim. Res. 39:31-46.

Lim, J. H., and Kim, S. D. 2009. Synergistic plant growth promotion by the indigenous auxins-producing PGPR Bacillus subtilis AH18 and Bacillus licheniforims K11. J. Korean Soc. Appl. Biol. Chem. 52: 531-538.

Liu, Y., Tao, J., Yan, Y., Li, B., Li, H., and Li, C. 2011. Biocontrol efficiency of Bacillus subtilis SL-13 and characterization of an antifungal chitinase. Chin. J. Chem. Eng. 19:128-134.

López, D., Fischbach, M. A., Chu, F., Losick, R., and Kolter, R. 2009. Structurally diverse natural products that cause potassium leakage trigger multicellularity in Bacillus subtilis. Proc. Natl. Acad. Sci. U.S.A 106:280-285

Lugtenberg, B., and Kamilova, F. 2009. Plant-growth-promoting rhizobacteria. Annu. Rev. Microbiol. 63:541-556.

Luo, C., Zhou, H., Zou, J., Wang, X., Zhang, R., Xiang, Y., and Chen, Z. 2015. Bacillomycin $L$ and surfactin contribute synergistically to the phenotypic features of Bacillus subtilis 916 and the biocontrol of rice sheath blight induced by Rhizoctonia solani. Appl. Microbiol. Biotechnol. 99:1897-1910.

Maplestone, P. A., and Campbell, R. 1989. Colonization of roots of wheat seedlings by bacilli proposed as biocontrol agents against take-all. Soil Biol. Biochem. 21:543-550.

Marlow, V. L., Porter, M., Hobley, L., Kiley, T. B., Swedlow, J. R., Davidson, F. A., and Stanley-Wall, N. R. 2014. Phosphorylated DegU manipulates cell fate differentiation in the Bacillus subtilis biofilm. J. Bacteriol. 196:16-27.

Mielich-Süss, B., and Lopez, D. 2015. Molecular mechanisms involved in Bacillus subtilis biofilm formation. Environ. Microbiol. 17:555-565.

Molina-Santiago, C., Pearson, J. R., Navarro, Y., Berlanga-Clavero, M. V., Caraballo-Rodriguez, A. M., Petras, D., García-Martín, M. L., Lamon, G., Haberstein, B., Cazorla, F. M., de Vicente, A., Loquet, A., Dorrestein, P. C., and Romero, D. 2019. The extracellular matrix protects Bacillus subtilis colonies from Pseudomonas invasion and modulates plant cocolonization. Nat. Commun. 10:1919.

Moreira, R. R., and De Mio, L. L. M. 2015. Potential biological agents isolated from apple fail to control Glomerella leaf spot in the field. Biol. Control 87:56-63.

Mukherjee, A. K., and Das, K. 2005. Correlation between diverse cyclic lipopeptides production and regulation of growth and substrate utilization by Bacillus subtilis strains in a particular habitat. FEMS Microbiol. Ecol 54:479-489.

Nagalingam, N. A., and Lynch, S. V. 2012. Role of the microbiota in inflammatory bowel diseases. Inflamm. Bowel Dis. 18:968-984. 
Nakano, M. M., and Zuber, P. 1991. The primary role of comA in establishment of the competent state in Bacillus subtilis is to activate expression of srfA. J. Bacteriol. 173:7269-7274.

Ogura, M., and Fujita, Y. 2007. Bacillus subtilis rapD, a direct target of transcription repression by RghR, negatively regulates srfA expression. FEMS Microbiol. Lett. 268:73-80.

Oliveira, N. M., Martinez-Garcia, E., Xavier, J., Durham, W. M., Kolter, R., Kim, W., and Foster, K. R. 2015. Biofilm formation as a response to ecological competition. PLoS Biol. 13:e1002191.

Omer Bendori, S., Pollak, S., Hizi, D., and Eldar, A. 2015. The RapP-PhrP quorum-sensing system of Bacillus subtilis strain NCIB3610 affects biofilm formation through multiple targets, due to an atypical signalinsensitive allele of RapP. J. Bacteriol. 197:592-602

Ongena, M., and Jacques, P. 2008. Bacillus lipopeptides: Versatile weapons for plant disease biocontrol. Trends Microbiol. 16:115-125.

Ongena, M., Jourdan, E., Adam, A., Paquot, M., Brans, A., Joris, B., Arpigny, J. L., and Thonart, P. 2007. Surfactin and fengycin lipopeptides of Bacillus subtilis as elicitors of induced systemic resistance in plants. Environ. Microbiol. 9:1084-1090.

Ordal, G. W., and Goldman, D. J. 1976. Chemotactic repellents of Bacillus subtilis. J. Mol. Biol. 100:103-108.

Pan, J., Huang, T., Yao, F., Huang, Z., Powell, C. A., Qiu, S., and Guan, X. 2008. Expression and characterization of aiiA gene from Bacillus subtilis BS-1. Microbiol. Res. 163:711-716.

Parashar, V., Konkol, M. A., Kearns, D. B., and Neiditch, M. B. 2013. A plasmid-encoded phosphatase regulates Bacillus subtilis biofilm architecture, sporulation, and genetic competence. J. Bacteriol. 195: 2437-2448.

Parashar, V., Mirouze, N., Dubnau, D. A., and Neiditch, M. B. 2011. Structural basis of response regulator dephosphorylation by Rap phosphatases. PLoS Biol. 9:e1000589.

Peng, G., McGregor, L., Lahlali, R., Gossen, B. D., Hwang, S. F., Adhikari, K. K., Strelkov, S. E., and McDonald, M. R. 2011. Potential biological control of clubroot on canola and crucifer vegetable crops. Plant Pathol 60:566-574.

Perego, M. 2013. Forty years in the making: Understanding the molecular mechanism of peptide regulation in bacterial development. PLoS Biol. 11:e1001516.

Pérez-García, A., Romero, D., and de Vicente, A. 2011. Plant protection and growth stimulation by microorganisms: Biotechnological applications of Bacilli in agriculture. Curr. Opin. Biotechnol. 22:187-193.

Pieterse, C. M., Zamioudis, C., Berendsen, R. L., Weller, D. M., Van Wees, S. C., and Bakker, P. A. 2014. Induced systemic resistance by beneficial microbes. Annu. Rev. Phytopathol. 52:347-375.

Pottathil, M., and Lazazzera, B. A. 2003. The extracellular Phr peptide-Rap phosphatase signaling circuit of Bacillus subtilis. Front. Biosci. 8: d32-d45.

Powers, M. J., Sanabria-Valentín, E., Bowers, A. A., and Shank, E. A. 2015. Inhibition of cell differentiation in Bacillus subtilis by Pseudomonas protegens. J. Bacteriol. 197:2129-2138.

Qiao, J., Yu, X., Liang, X., Liu, Y., Borriss, R., and Liu, Y. 2017. Addition of plant-growth-promoting Bacillus subtilis PTS-394 on tomato rhizosphere has no durable impact on composition of root microbiome. BMC Microbiol. 17:131.

Qin, J., Li, Y., Cai, Z., Li, S., Zhu, J., Zhang, F., Liang, S., Zhang, W., Guan, Y., Shen, D., Peng, Y., Zhang, D., Jie, Z., Wu, W., Qin, Y., Xue, W., Li, J., Han, L., Lu, D., Wu, P., Dai, Y., Sun, X., Li, Z., Tang, A., Zhong, S., Li, X., Chen, W., Xu, R., Wang, M., Feng, Q., Gong, M., Yu, J., Zhang, Y., Zhang, M., Hansen, T., Sanchez, G., Raes, J., Falony, G., Okuda, S., Almeida, M., LeChatelier, E., Renault, P., Pons, N., Batto, J.-M., Zhang, Z., Chen, H., Yang, R., Zheng, W., Li, S., Yang, H., Wang, J., Ehrlich, S. D., Nielsen, R., Pedersen, O., Kristiansen, K., and Wang, J. 2012. A metagenome-wide association study of gut microbiota in type 2 diabetes. Nature 490:55-60.

Rao, C. V., Kirby, J. R., and Arkin, A. P. 2004. Design and diversity in bacterial chemotaxis: A comparative study in Escherichia coli and Bacillus subtilis. PLoS Biol. 2:e49.

Rekha, K., Kumar, R. M., Ilango, K., Rex, A., and Usha, B. 2018. Transcriptome profiling of rice roots in early response to Bacillus subtilis (RR4) colonization. Botany 96:749-765.

Rudrappa, T., Czymmek, K. J., Paré, P. W., and Bais, H. P. 2008. Rootsecreted malic acid recruits beneficial soil bacteria. Plant Physiol. 148: 1547-1556.

Ryu, C. M., Farag, M. A., Hu, C. H., Reddy, M. S., Kloepper, J. W., and Paré, P. W. 2004. Bacterial volatiles induce systemic resistance in Arabidopsis. Plant Physiol. 134:1017-1026.

Ryu, C. M., Farag, M. A., Hu, C. H., Reddy, M. S., Wei, H. X., Paré, P. W., and Kloepper, J. W. 2003. Bacterial volatiles promote growth in Arabidopsis. Proc. Natl. Acad. Sci. U.S.A. 100:4927-4932.
Saeid, A., Prochownik, E., and Dobrowolska-Iwanek, J. 2018. Phosphorus solubilization by Bacillus species. Molecules 23:2897.

Sansinenea, E., and Ortiz, A. 2011. Secondary metabolites of soil Bacillus spp. Biotechnol. Lett. 33:1523-1538.

Sasse, J., Martinoia, E., and Northen, T. 2018. Feed your friends: Do plant exudates shape the root microbiome? Trends Plant Sci. 23:25-41.

Schisler, D. A., Slininger, P. J., Behle, R. W., and Jackson, M. A. 2004 Formulation of Bacillus spp. for biological control of plant diseases. Phytopathology 94:1267-1271.

Shemesh, M., and Chai, Y. 2013. A combination of glycerol and manganese promotes biofilm formation in Bacillus subtilis via histidine kinase KinD signaling. J. Bacteriol. 195:2747-2754.

Shoda, M. 2000. Bacterial control of plant diseases. J. Biosci. Bioeng. 89: 515-521.

Sivasakthi, S., Usharani, G., and Saranraj, P. 2014. Biocontrol potentiality of plant growth promoting bacteria (PGPR)-Pseudomonas fluorescens and Bacillus subtilis: A review. Afr. J. Agric. Res. 9: 1265-1277.

Stefanic, P., Kraigher, B., Lyons, N. A., Kolter, R., and Mandic-Mulec, I. 2015. Kin discrimination between sympatric Bacillus subtilis isolates. Proc. Natl. Acad. Sci. U.S.A. 112:14042-14047

Stein, T. 2005. Bacillus subtilis antibiotics: Structures, syntheses and specific functions. Mol. Microbiol. 56:845-857.

Tao, C., Li, R., Xiong, W., Shen, Z., Liu, S., Wang, B., Ruan, Y., Geisen, S., Shen, Q., and Kowalchuk, G. A. 2020. Bio-organic fertilizers stimulate indigenous soil Pseudomonas populations to enhance plant disease suppression. Microbiome 8:137.

Thérien, M., Kiesewalter, H. T., Auria, E., Charron-Lamoureux, V., Wibowo, M., Maróti, G., Kovács, A. T., and Beauregard, P. B. 2020. Surfactin production is not essential for pellicle and root-associated biofilm development of Bacillus subtilis. Biofilm 2:100021.

Todorova, S., and Kozhuharova, L. 2010. Characteristics and antimicrobial activity of Bacillus subtilis strains isolated from soil. World J. Microbiol. Biotechnol. 26:1207-1216.

Townsley, L., Yannarell, S. M., Huynh, T. N., Woodward, J. J., and Shank, E. A. 2018. Cyclic di-AMP acts as an extracellular signal that impacts Bacillus subtilis biofilm formation and plant attachment. MBio 9 e00341-18.

Trivedi, P., Leach, J. E., Tringe, S. G., Sa, T., and Singh, B. K. 2020. Plantmicrobiome interactions: From community assembly to plant health. Nat. Rev. Microbiol. 18:607-621.

van Gestel, J., Vlamakis, H., and Kolter, R. 2015. Division of labor in biofilms: The ecology of cell differentiation. Microbiol. Spectr. 3:MB0002-2014

Verhamme, D. T., Kiley, T. B., and Stanley-Wall, N. R. 2007. DegU coordinates multicellular behaviour exhibited by Bacillus subtilis. Mol Microbiol. 65:554-568.

Verma, P. P., Shelake, R. M., Das, S., Sharma, P., and Kim, J. Y. 2019. Plant growth-promoting rhizobacteria (PGPR) and fungi (PGPF): potential biological control agents of diseases and pests. Pages 281-311 in: Microbial Interventions in Agriculture and Environment. Springer, Singapore.

Vlamakis, H., Chai, Y., Beauregard, P., Losick, R., and Kolter, R. 2013. Sticking together: Building a biofilm the Bacillus subtilis way. Nat. Rev. Microbiol. 11:157-168.

von Bodman, S. B., Willey, J. M., and Diggle, S. P. 2008. Cell-cell communication in bacteria: United we stand. J. Bacteriol. 190: 4377-4391.

Walukiewicz, H. E., Tohidifar, P., Ordal, G. W., and Rao, C. V. 2014 Interactions among the three adaptation systems of Bacillus subtilis chemotaxis as revealed by an in vitro receptor-kinase assay. Mol. Microbiol. 93:1104-1118.

Wang, T., Liang, Y., Wu, M., Chen, Z., Lin, J., and Yang, L. 2015. Natural products from Bacillus subtilis with antimicrobial properties. Chin. J. Chem. Eng. 23:744-754.

Ward, E., Kim, E. A., Panushka, J., Botelho, T., Meyer, T., Kearns, D. B., Ordal, G., and Blair, D. F. 2019. Organization of the flagellar switch complex of Bacillus subtilis. J. Bacteriol. 201:e00626-18.

Wei, F., Hu, X., and Xu, X. 2016. Dispersal of Bacillus subtilis and its effect on strawberry phyllosphere microbiota under open field and protection conditions. Sci. Rep. 6:22611.

Woo, O. G., Kim, H., Kim, J. S., Keum, H. L., Lee, K. C., Sul, W. J., and Lee, J. H. 2020. Bacillus subtilis strain GOT9 confers enhanced tolerance to drought and salt stresses in Arabidopsis thaliana and Brassica campestris. Plant Physiol. Biochem. 148:359-367.

Xie, S. S., Wu, H. J., Zang, H. Y., Wu, L. M., Zhu, Q. Q., and Gao, X. W. 2014. Plant growth promotion by spermidine-producing Bacillus subtilis OKB105. Mol. Plant-Microbe Interact 27:655-663. 
Xu, X. M., Jeffries, P., Pautasso, M., and Jeger, M. J. 2011. Combined use of biocontrol agents to manage plant diseases in theory and practice. Phytopathology 101:1024-1031.

Yang, Y., Wu, H. J., Lin, L., Zhu, Q. Q., Borriss, R., and Gao, X. W. 2015. A plasmid-born Rap-Phr system regulates surfactin production, sporulation and genetic competence in the heterologous host, Bacillus subtilis OKB105. Appl. Microbiol. Biotechnol. 99:7241-7252.

Yu, Y., Yan, F., Chen, Y., Jin, C., Guo, J. H., and Chai, Y. 2016. Poly$\gamma$-glutamic acids contribute to biofilm formation and plant root colonization in selected environmental isolates of Bacillus subtilis. Front. Microbiol. 7:1811.

Zhang, H., Kim, M. S., Krishnamachari, V., Payton, P., Sun, Y., Grimson, M., Farag, M. A., Ryu, C.-M., Allen, R., Melo, I. S., and Paré, P. W. 2007. Rhizobacterial volatile emissions regulate auxin homeostasis and cell expansion in Arabidopsis. Planta 226:839-851.
Zhang, H., Kim, M. S., Sun, Y., Dowd, S. E., Shi, H., and Paré, P. W. 2008. Soil bacteria confer plant salt tolerance by tissue-specific regulation of the sodium transporter HKT1. Mol. Plant-Microbe Interact 21: 737-744.

Zhang, H., Murzello, C., Sun, Y., Kim, M. S., Xie, X., Jeter, R. M., Zak, J. C., Dowd, S. E., and Paré, P. W. 2010. Choline and osmotic-stress tolerance induced in Arabidopsis by the soil microbe Bacillus subtilis (GB03). Mol. Plant-Microbe Interact 23:1097-1104.

Zhang, H., Sun, Y., Xie, X., Kim, M. S., Dowd, S. E., and Paré, P. W. 2009. A soil bacterium regulates plant acquisition of iron via deficiencyinducible mechanisms. Plant J. 58:568-577.

Zhang, N., Wang, D., Liu, Y., Li, S., Shen, Q., and Zhang, R. 2014. Effects of different plant root exudates and their organic acid components on chemotaxis, biofilm formation and colonization by beneficial rhizosphereassociated bacterial strains. Plant Soil 374:689-700. 